\title{
Seismic behavior of MSCSS based on story drift and failure path
}

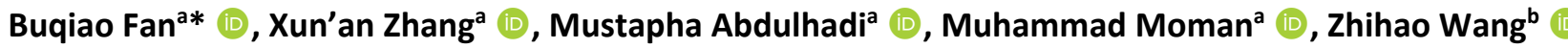 \\ a School of Mechanics, Civil Engineering and Architecture, Northwestern Polytechnical University, Xi'an, China. Email: \\ buqiao@mail.nwpu.edu.cn, jiaoping@nwpu.edu.cn, engineermustapha@yahoo.com,m.mominshahzad@mail.nwpu.edu.cn \\ ${ }^{\mathrm{b}}$ School of Civil Engineering and Communication, North China University of Water Resources and Electric Power, Zhengzhou, China. \\ Email: wangzhihao@ncwu.edu.cn
}

* Corresponding author

https://doi.org/10.1590/1679-78256787

\begin{abstract}
The Mega-Sub Controlled Structure System (MSCSS) is a new type of seismic structural system. This research aims to find weak members in the structure and better describe the failure state. To achieve this, we enhanced the story drift ratio indicator by combining it with the structural failure path and proposed a new comprehensive indicator that can more accurately describe the seismic behavior of the structure. The new concept of seismic behavior is proposed. The seismic waves used in the analysis in this article are generated by the Hilbert-Huang transformation method. The failure path of the structure under random seismic waves is calculated by the weighted rank-sum ratio method. The comprehensive indicator is checked on the MSCSS with or without lead-rubber bearings and traditional Mega-Sub structure. The calculation results show that the story drift ratio alone cannot fully reflect the damage of structures in earthquakes. The new indicator combined with the failure path can describe the seismic behavior of the MSCSS more comprehensively and can better assist the seismic design and optimization of structures.
\end{abstract}

\section{Keywords}

MSCSS, failure path, seismic behavior, rubber bearing, weighted rank-sum ratio, mega-frame.

\section{Graphical abstract}
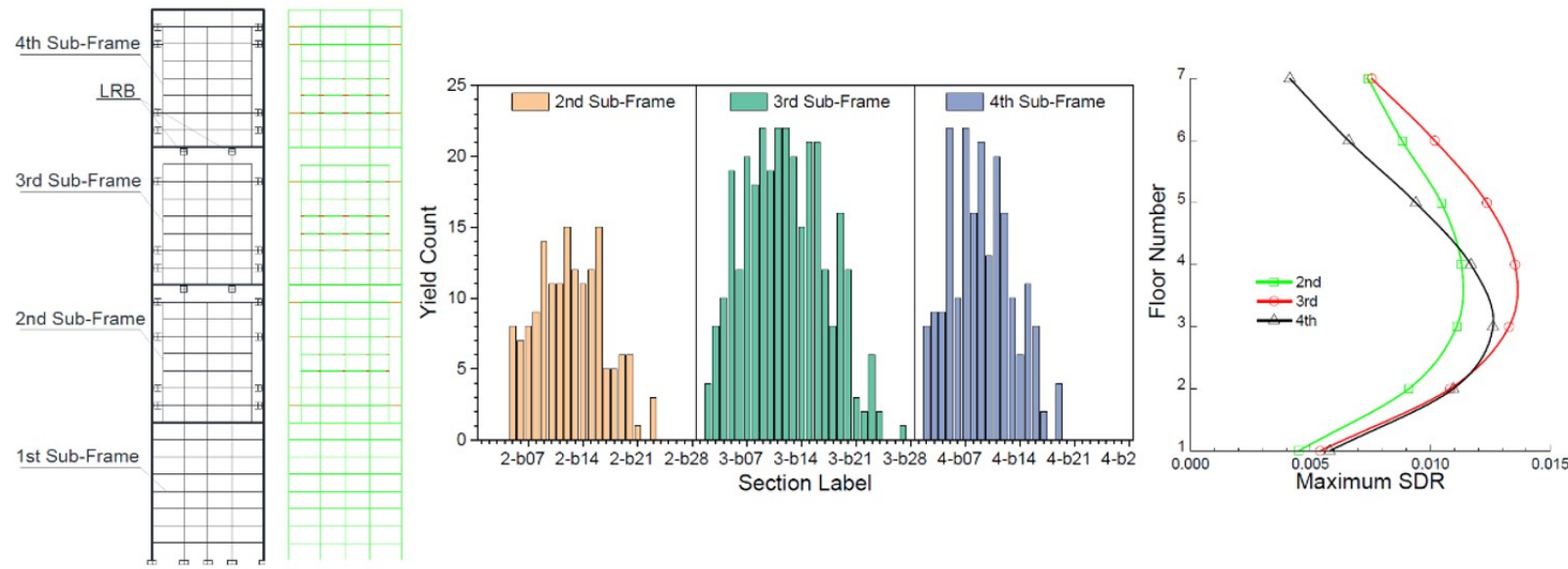


\section{INTRODUCTION}

Earthquakes can damage buildings and cause extensive loss of life and property. High-rise buildings are especially susceptible to earthquakes due to their high flexibility and low inherent damping. There are many control strategies used to mitigate the vibration of high-rise buildings during earthquakes. One common strategy is to isolate the whole or part of the structure from the ground motion. The isolation layer can be placed at the base (Jangid and Datta 1995; Hwang and Chiou 1996; Jangid 2007; Providakis 2008; Kilar and Koren 2009; Mishra et al. 2013; Hessabi et al. 2017; Deringol and Bilgin 2018; Kontoni and Farghaly 2019) or between floors) of the building (Ryan and Earl 2010; Warn and Ryan 2012; Reggio and De Angelis 2015; Liu et al. 2018; Kim and Kang 2019; Dona et al. 2021. Another strategy is to adopt energyabsorbing systems on buildings to dissipate seismic energy. The tuned mass damper (TMD) system is one of the most widely used systems that has been applied to many actual structures (Sadek et al. 1997; Li et al. 2011; Soto and Adeli 2013; Elias and Matsagar 2017; Espinoza et al. 2018a, 2018b; Zhou et al. 2018; Chen et al. 2019; Zhang 2019; Snamina and Orkisz 2021).

The structural system studied in this paper, the Mega Sub-Control Structure System (MSCSS), is a new structural system. It integrates the ideas of frequency tuning and energy dissipation of TMD into the Mega-Sub Structure (MSS) system. The new system has better vibration control during earthquakes than the traditional MSS, and at the same time, overcomes many problems that existed in the TMD system. The MSCSS takes advantage of the MSS system and uses its sub-frame, which is part of the structure, as the tuned mass in TMD, so no additional tuned mass is needed. Compared with TMD, MSCSS not only eliminates the extra weights and safety hazards imposed by the additional tuned mass but can also achieve a tuned mass to total mass ratio of 50\% (Limazie et al. 2013), which the TMD can never reach; hence MSCSS can dissipate more energy during earthquakes and have significantly less vibration (Fan et al. 2020).

After Feng and Mita (1995) proposed the idea of combining TMD with MSS, Feng and Chai (1997), Zhang et al. (2005), (2009) and Limazie et al. (2013) have continuously improved and developed the theory of MSCSS. Zhang et al. (2005)] established a more realistic analysis model and studied the range of the optimal relative mass ratio and relative stiffness ratio of MSCSS to achieve the best vibration control under random wind loads. Later, Zhang et al. (2009) studied the response of MSCSS under the action of simulated ground motion represented by static and non-stationary random processes. In the study, additional columns, as shown in Figure 1, are added above each MSCSS sub-frame to reduce the excessive bending moments in mega-beams so that the larger spans of the mega-beams can be achieved. Fan et al. (2020) and Abdulhadi et al. (2020) have demonstrated that if lead rubber bearings (LRBs) are installed between the additional columns and the mega-beams as shown in Figure 1, that is to release the connections between sub-frames and the upper mega-beams, the seismic performance of MSCSS can be further improved.
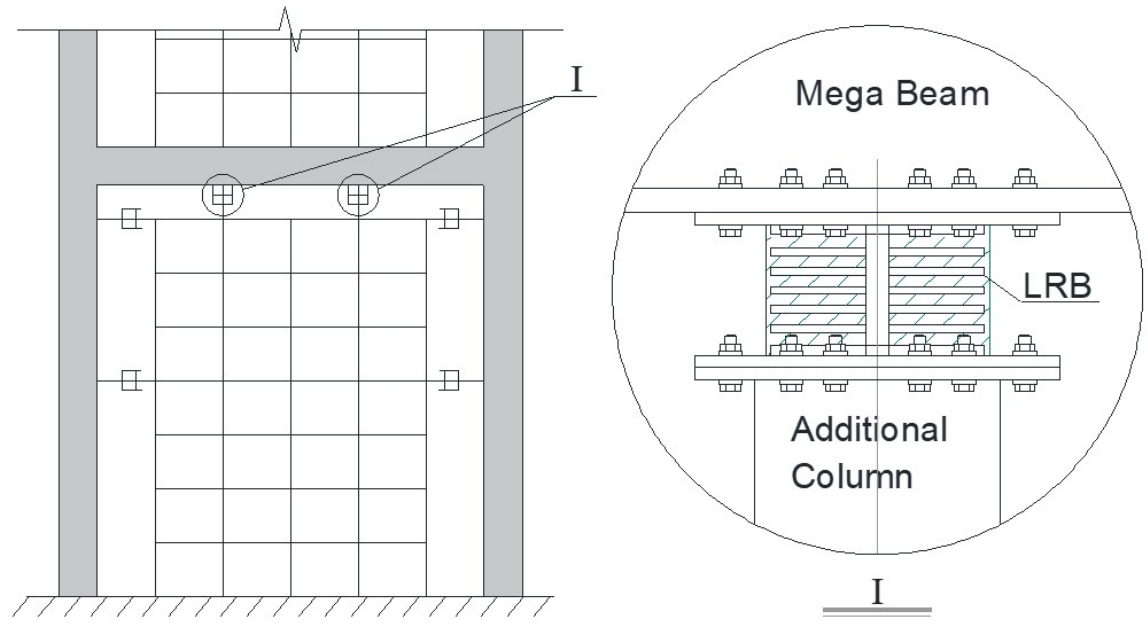

Figure 1 LRB on the additional column.

In the past, most studies on MSCSS used the story drift ratio (SDR), acceleration, or energy dissipation as indicators to measure the effect of vibration control (Zhang et al. 2005, 2009; Limazie et al. 2013; Fan et al. 2020). These indicators can reflect the overall response of the structure, but they cannot show the failing process of structural members during strong earthquakes. Through the analysis of the failure path of the structure, the local damages and potential failure modes of the structure can be explored. Fu and Li (2018) studied the failure paths of tower structures under wind load and identified all potential failure modes of the structures. Later, Fu et al. (2020) studied the tension tower's stress state 
and failure path under multiple loading conditions. Shao and Billington (2020) studied the failure paths of concrete beams with different reinforcements under monotonic and cyclic loading. These studies have calculated the failure paths of structures or components under deterministic loads. In this paper, structures are analyzed under 50 different earthquakes, and failure paths are calculated using the weighted rank-sum ratio method (Sang et al. 2014; Fu et al. 2015; Tan et al. 2017). To measure the impact of earthquake action at both the floor level and the structural member level, the seismic behavior matrix is proposed as a new indicator.

The rest of this paper is organized as follows. First, the weighted rank-sum ratio method is introduced to calculate the failure paths. By combining the SDR and the failure path, the new concept of seismic behavior is proposed to be a more informative seismic performance indicator. Subsequently, the calculation of failure paths and seismic behavior matrices has been demonstrated using finite element models established under ABAQUS. The failure modes of different structure systems are discussed. Compared with MSS and traditional MSCSS, MSCSS with rubber bearing shows superiority in seismic behavior. Based on the analysis results, optimization suggestions are proposed for the seismic design of the MSCSS.

\section{Calculation Method of Failure Path}

When MSCSS fails in strong earthquakes, structural members of MSCSS gradually enter from the elastic stage to the plastic stage. As more and more plastic hinges form in the structure, some members quit working, and the stress is redistributed to the other members. When plastic hinges occur in certain critical locations of the structure, it will trigger one of many potential failure modes, causing the overall structure to collapse. Studying the distribution and development path of plastic hinges, i.e., the structure's failure path, helps evaluate the seismic performance and guide the design and optimization.

Failure path analysis is widely used to assess structural damage (Fu and Li 2018; Chau et al. 2020; Shao and Billington 2020). Previous studies often use one or several determined seismic waves and use push-over analysis to find one or several definite failure paths. However, seismic waves in the real world are random, so the failure path is also random. This study proposes a new method to calculate the most likely failure path under random seismic waves. The most probable failure path is found by analyzing the structure under multiple seismic waves, calculating the weighted ranksum ratios of investigation sections on each member, and determining the yield order according to the sizes of the weighted rank-sum ratios.

\section{Generation of seismic waves}

Because seismic waves are stochastic processes, a sufficient number of seismic waves must be used to analyze the structure to obtain statistically significant results. To generate a set of waves with the same spectral characteristics, the horizontal acceleration of El. Centro NS is used as the mother wave. The non-stationary power spectrum of the wave is extracted using the Hilbert-Huang transformation (HHT) method (Fan et al. 2017, 2020; Zhu et al. 2017; Garcia et al. 2019). The generated seismic waves are adjusted to the same acceleration peak value. The method of generating seismic waves is described in detail in Fan et al. (2020).

\section{Weighted rank-sum ratio method}

To get the failure path of a structure under a single seismic wave, we just need to sort the investigation sections according to their yield order. When the analysis is performed under multiple seismic waves, the yield order of sections under different seismic waves may differ. The yield orders need to be normalized to a dimensionless number to find the most probable failure path. This paper uses the Weighted Rank-Sum Ratio (WRSR) as the dimensionless number to represent the yield orders.

WRSR method is improved based on the rank-sum ratio (RSR) method. RSR is a statistical method proposed by Tian (1993). It combines the advantages of classical parameter estimation and modern non-parametric statistics. It is widely used in multi-target evaluation in medical and health work (Gu et al. 2020; Tian et al. 2020). The procedure of the RSR method is as follows: first, establish an $n \times m$ rank matrix, where $n$ is the number of evaluation objects and $m$ is the number of evaluation indicators. The $R_{i j}$ is the ranking of the object $i$ in the total of $n$ objects when evaluated under indicator $j$. The dimensionless RSR for object $i$ can be calculated with the following formula:

$$
\zeta_{\mathrm{RSR}, i}=\frac{1}{n \times m} \sum_{j=1}^{m} R_{i j}
$$


$\zeta_{\mathrm{RSR}}$ is a continuous non-parametric statistical value in the interval $[0,1]$. The larger the value of $\zeta_{\mathrm{RSR}}$, the better the evaluated object.

In Eq. $\zeta_{\mathrm{RSR}, i}=\frac{1}{n \times m} \sum_{j=1}^{m} R_{i j} \quad(1)$, each indicator has the same weight, which is reflected in Eq. $\zeta_{\mathrm{RSR}, i}=\frac{1}{n \times m} \sum_{j=1}^{m} R_{i j}$ (1) that the summed ratio is averaged by dividing by $m$. When the weights of the various indicators are different, a weight coefficient for each indicator can be introduced to improve the RSR. The method is called the WRSR method. The WRSR for object $i, \zeta_{\mathrm{WRSR}, i}$, can be calculated as:

$\zeta_{\mathrm{WRSR}, i}=\frac{1}{n} \sum_{j=1}^{m} W_{j} R_{i j}$

$W_{j}$ is the weight coefficient of the indicator $j$, and $\sum_{j=1}^{m} W_{j}=1$.

Specific to the structure discussed in this paper, the evaluation objects are the investigation sections of the structural members, and $m$ is the number of the seismic waves. Each evaluation indicator is the analysis result obtained from each seismic wave, and $n$ is the number of the investigated sections. The ranking $R_{i j}$ is the sequence of the investigation section $i$ entering the plastic phase under the seismic wave $j$. If section $i$ does not yield under wave $j$, then $R_{i j}=0$. The weight coefficient $W_{j}$ is the absolute value of the ratio of the yield acceleration of a section under the $j$ th seismic wave to the sum of the yield acceleration of the section under all seismic waves. Here, the yield acceleration is defined as the horizontal acceleration of the section when it first fully enters the plastic state.

\section{Seismic behavior of the structures}

In China's National Building Code GB50011 (2010), the maximum SDR is used as the control factor for seismic design. SDR in this paper is defined as the relative displacement between two adjacent sub-floors divided by sub-story height. The SDR only reflects the overall deformation of floors, not the damage to each member on each floor. To reflect both factors of overall structural deformation and individual member damage, the concept of seismic behavior is proposed. The seismic behavior of structures, $\mathbf{r}$, can be mathematically expressed through the following equation:

$\mathbf{r}=\left[\left[\Delta_{1}, \Delta_{2}, \cdots, \Delta_{n}\right]^{T},\left[\delta_{1}, \delta_{2}, \cdots, \delta_{m}\right]\right]$

$\left[\Delta_{1}, \Delta_{2}, \cdots, \Delta_{n}\right]^{T}$ in Eq. $\mathbf{r}=\left[\left[\Delta_{1}, \Delta_{2}, \cdots, \Delta_{n}\right]^{T},\left[\delta_{1}, \delta_{2}, \cdots, \delta_{m}\right]\right]$ (3) is the maximum SDR vector, where $\Delta_{n}$ is the maximum SDR for the $n$-th story. The vector is obtained by averaging the results from multiple seismic waves. $\left[\delta_{1}, \delta_{2}, \cdots, \delta_{m}\right]^{T}$ is the failure path vector of the structure. Each entry in the vector is the sequence number of a member section on the failure path. The subscript $m$ indicates that there are a total of $m$ sections of interest. These cross-sections are distributed in $k$ stories, where $k \leq n$. Then, the seismic behavior matrix can be expanded as:

$\left.\mathbf{r}=\left[\begin{array}{c}\Delta_{1} \\ \Delta_{2} \\ \vdots \\ \Delta_{n}\end{array}\right]\left[\begin{array}{cccc}\delta_{11} & \delta_{12} & \cdots & \delta_{1 m_{1}} \\ \delta_{21} & \delta_{22} & \cdots & \delta_{2 m_{2}} \\ \vdots & \vdots & & \vdots \\ \delta_{k 1} & \delta_{k 2} & \cdots & \delta_{k m_{k}}\end{array}\right]\right]$ 
When the total number of stories is the same as the number of stories investigated, $k=n$. When the number of crosssections examined on each story is the same, $m_{1}=m_{2}=\cdots=m_{k}=m$. The seismic behavior matrix can be rewritten as:

$\mathbf{r}=\left[\begin{array}{ccccc}\Delta_{1} & \delta_{11} & \delta_{11} & \cdots & \delta_{1 m} \\ \Delta_{2} & \delta_{21} & \delta_{22} & \cdots & \delta_{2 m} \\ \vdots & \vdots & \vdots & & \vdots \\ \Delta_{n} & \delta_{n 1} & \delta_{n 2} & \cdots & \delta_{n m}\end{array}\right]$

\section{Computational Examples}

\section{Finite element models}

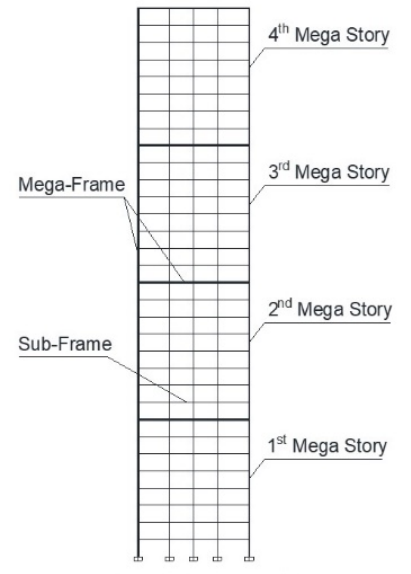

(a) MSS (Model I)

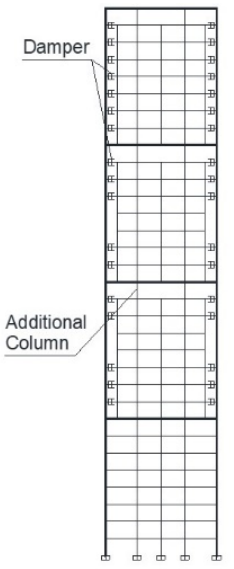

(b) MSCSS without LRBs (Model II)

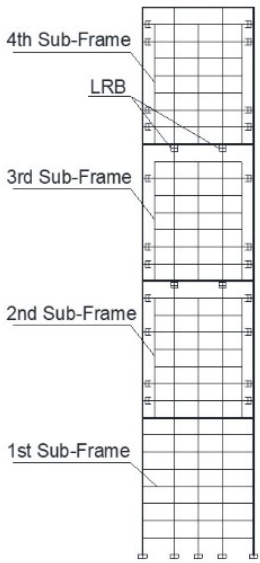

(c) MSCSS with LRBs (Model III)

Figure 2 Models of different structural systems.

Table 1 Member section properties.

\begin{tabular}{cc}
\hline Member & Cross-section $(\mathrm{m})$ \\
\hline $1^{\text {st }}$ Story Mega-beam & $\mathrm{H} 1.8 \times 1.8 \times 0.060 \times 0.060$ \\
$2^{\text {nd }}$ Story Mega-beam & $\mathrm{H} 1.6 \times 1.6 \times 0.040 \times 0.040$ \\
$3^{\text {rd }}$ Story Mega-beam & $\mathrm{H} 1.5 \times 1.5 \times 0.024 \times 0.024$ \\
$4^{\text {th }}$ Story Mega-beam & $\mathrm{H} 1.5 \times 1.5 \times 0.016 \times 0.016$ \\
$1^{\text {st }}$ Story Mega-column & $\square 1.6 \times 1.6 \times 0.060 \times 0.080$ \\
$2^{\text {nd }}$ Story Mega-column & $\square 1.6 \times 1.6 \times 0.040 \times 0.060$ \\
$3^{\text {rd }}$ Story Mega-column & $\square 1.5 \times 1.5 \times 0.030 \times 0.030$ \\
$4^{\text {th }}$ Story Mega-column & $\square 1.5 \times 1.5 \times 0.020 \times 0.020$ \\
Sub-beam & $\mathrm{H} 0.3 \times 0.3 \times 0.008 \times 0.008$ \\
Sub-column & $\square 0.5 \times 0.5 \times 0.030 \times 0.030$ \\
\hline
\end{tabular}

The difference between the three models is their vibration control system. Model I is a conventional MSS without any vibration control system. Model II and Model III are both MSCSS. The difference between Model II and III is that LRBs 
are installed on the top of some additional columns of Model III. The parameters and distributions of energy dissipaters, namely dampers and LRBs, adopt the optimization results from Fan et al. (2020).

The HHT method was used to generate 50 seismic waves with a peak acceleration of 800gal and a duration of 53.76 seconds. After analyzing the models under each seismic wave, a Python script was used to search through output database files generated by ABAQUS to find the beam elements that deform plastically. The time and acceleration at the first plastic deformation of each element were recorded.

All frames are modeled by beam elements B21. Dampers and LRBs are modeled by connector elements CONN2D2, with "axial" connection type for dampers and "Cartesian + Rotation" for LRBs. By adding inertia non-structure mass, a dead load of $1020 \mathrm{~kg} / \mathrm{m}$ is applied along the length of beams. The model is submitted to the ABAQUS dynamic implicit solver for analysis. The time history analysis uses a fixed $0.02 \mathrm{sec}$ increment size.

\section{Investigation sections}

Damages of frame structure during an earthquake often occur at the ends of members, and that is where we set up investigation sections. Since the studied models are all symmetrical, the probabilities of plastic deformation on the left and right sides of the symmetric axis are the same. Only the left side of each model is investigated. For ease of description, the investigation sections are labeled and demonstrated in Figure 3. In each label, the number before the hyphen is the mega-floor number. The letter after the hyphen indicates whether it is on a beam or a column. Capital letters are for the mega-frame sections, while lowercase letters are for the sub-frame sections. The last two digits after the label are the section number for beams and columns counted from left to right and from bottom to top. The labeling method is similar for all three models. The number of investigation sections in each model is shown in Table 2.

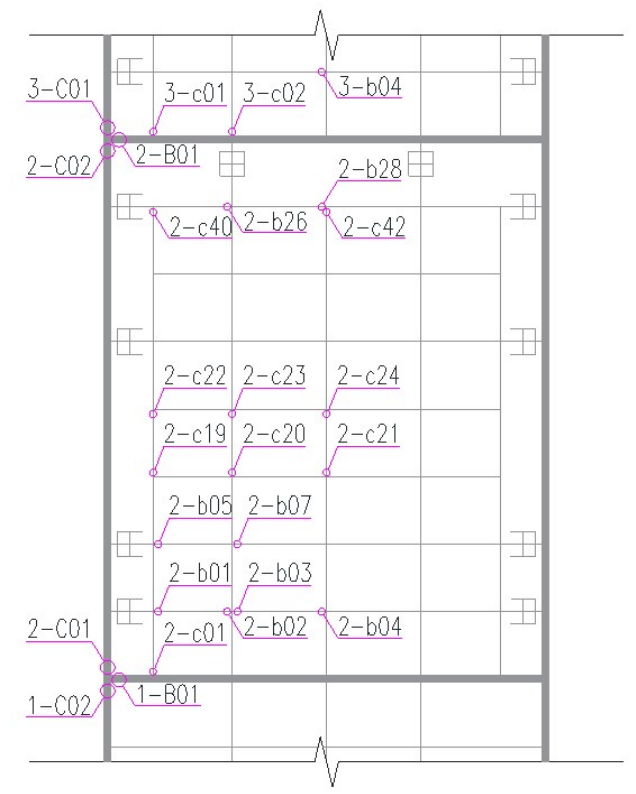

Figure 3 Labeling of investigation sections.

Table 2 Number of investigation sections.

\begin{tabular}{cccccc}
\hline & Sub-beam & Sub-column & Mega-beam & Mega-column & Total \\
\hline Model I & 112 & 128 & 4 & 8 & 252 \\
Model II \& III & 112 & 164 & 4 & 8 & 288 \\
\hline
\end{tabular}

\section{Results and discussion}

\section{Damages on different structural systems}

Using the HHT method mentioned above, 50 seismic waves are generated and denoted as EL01 EL50. The three different structure systems are analyzed under the 50 waves. Model I yielded under 49 out of the 50 seismic waves, Model II yielded under 44 seismic waves, and Model III yielded only under 29 seismic waves. It can be seen from the analysis results that Model III, the MSCSS with LRBs, has significantly better seismic performance than the other two 
structure systems. It remains intact in 21 strong earthquakes. Although the 50 artificial waves are generated from the same mother wave, the severity of damages they caused to the structures and the locations of the plastic deformation are very different. If only one or a few deterministic seismic waves are used to calculate the failure path, the results may deviate far from the actual situation. Therefore, it is necessary to find statistically significant failure paths through multiple seismic waves.

Due to the similarities of the three models, the most severe damages are caused by the same waves. EL5, EL13, EL26, and EL44 are the most destructive waves. The locations and extent of damage caused by seismic waves on different models are different. After models are analyzed through the ABAQUS dynamic implicit solver, a Python script is used to search through the CAE database files generated by ABAQUS to find the beam elements that undergo plastic deformations. The yield elements are highlighted in red in the ABAQUS viewport. The yielded investigated sections can be observed. It can be seen from the result, compared with the other two models, Model III has the least number of yielded sections. Figure 4 shows the plastic deformation of the three models after seismic waves EL21 and EL34. The number of yielding sections in Model III is far less than that in the other two models. Model I not only yielded the most in the sub-frames, but the mega-beams and columns are also seriously damaged, which are difficult to repair, and may cause the overall failure of the structure.

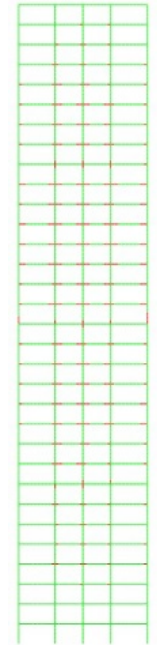

(a) Model I under EL21

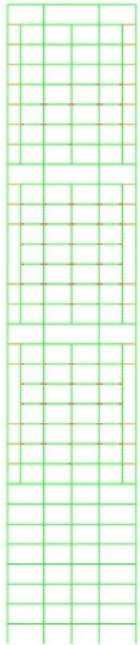

(b) Model II under EL21

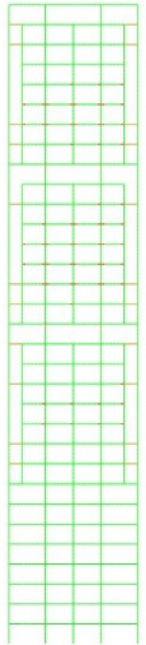

(c) Model III under EL21

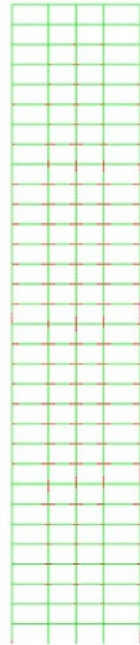

(d) Model I under EL34

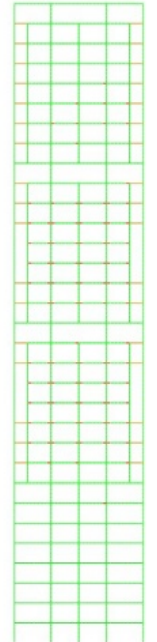

(e) Model II under EL34

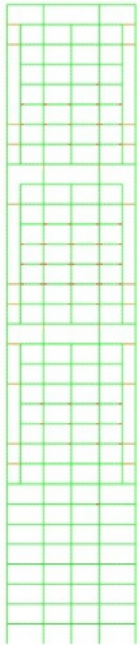

(f) Model III under EL34

Figure 4 Plastic deformation of different structural systems.

\section{Failure paths for different structure systems}

According to the yield order of each investigation section under each seismic wave and the corresponding acceleration at the time of yielding, the weighted rank-sum ratio $\zeta_{\text {WRSR }}$ of each investigation section is calculated. Investigation sections are sorted ascendingly by $\zeta_{\mathrm{WRSR}}$, and the failure paths of the structures are obtained. Table 3, Table 4, and Table 5 show the failure paths of the three models, respectively. Only the sections that yielded are shown in the tables. The sections with smaller $\zeta_{W R S R}$ are more likely to yield early in an earthquake. The sections with larger $\zeta_{\text {WRSR }}$ and the never yielded sections that are not listed in the tables are resilient. The tables show that Model III has significantly fewer yielded sections than the other two models; only 66 out of 288 sections have yielded. Model II has more yielded sections, 75 out of 288. Model I has the most yielded sections, that is 125 out of 252. The MSCSS with LRBs system shows the best seismic performance.

According to the failure paths of the three models, the damage always starts from the second and third sub-frames, then propagates to the fourth sub-frame, and then to the first sub-frame. For each sub-frame, the damage first appears on the sub-beams of the second, third, and fourth sub-floors, then gradually propagates to other sub-floors. The subbeams yield before the sub-columns, and the sub-frames yield before the mega-frames. There is almost no damage to the mega frames of Model II and Model III, but the damage to the mega-frame of Model I is severe. 
Table 3 Failure path for Model I.

\begin{tabular}{|c|c|c|c|c|c|c|c|c|c|c|c|c|c|c|}
\hline $\begin{array}{l}\text { Yield } \\
\text { Order }\end{array}$ & $\zeta_{\mathrm{WRSR}}$ & $\begin{array}{c}\text { Section } \\
\text { Label }\end{array}$ & $\begin{array}{l}\text { Yield } \\
\text { Order }\end{array}$ & $\zeta_{\text {WRSR }}$ & $\begin{array}{c}\text { Section } \\
\text { Label }\end{array}$ & $\begin{array}{l}\text { Yield } \\
\text { Order }\end{array}$ & $\zeta_{W R S R}$ & $\begin{array}{c}\text { Section } \\
\text { Label }\end{array}$ & $\begin{array}{l}\text { Yield } \\
\text { Order }\end{array}$ & $\zeta_{\text {WRSR }}$ & $\begin{array}{c}\text { Section } \\
\text { Label }\end{array}$ & $\begin{array}{l}\text { Yield } \\
\text { Order }\end{array}$ & $\zeta_{\text {WRSR }}$ & $\begin{array}{c}\text { Section } \\
\text { Label }\end{array}$ \\
\hline 1 & 0.097 & 2-b15 & 26 & 0.275 & 2-b27 & 51 & 0.386 & 3-b05 & 76 & 0.501 & 1-b25 & 101 & 0.609 & 1-b17 \\
\hline 2 & 0.102 & 2-b16 & 27 & 0.278 & 2-b03 & 52 & 0.389 & 2-b14 & 77 & 0.503 & $2-b 25$ & 102 & 0.616 & $4-\mathrm{cO} 2$ \\
\hline 3 & 0.106 & 2-b11 & 28 & 0.281 & 3-b09 & 53 & 0.393 & 4-b19 & 78 & 0.509 & $2-b 22$ & 103 & 0.617 & 1-b18 \\
\hline 4 & 0.107 & 3-b15 & 29 & 0.287 & 4-b11 & 54 & 0.393 & 2-b18 & 79 & 0.514 & 1-b13 & 104 & 0.623 & $3-c 31$ \\
\hline 5 & 0.108 & 3-b11 & 30 & 0.287 & $1-b 20$ & 55 & 0.396 & 4-b04 & 80 & 0.527 & $2-b 21$ & 105 & 0.624 & 4-b05 \\
\hline 6 & 0.114 & 3-b16 & 31 & 0.289 & $3-b 28$ & 56 & 0.396 & 4-b08 & 81 & 0.530 & 1-b07 & 106 & 0.627 & 4-b28 \\
\hline 7 & 0.116 & 2-b12 & 32 & 0.289 & $2-b 28$ & 57 & 0.400 & $2-b 26$ & 82 & 0.535 & 2-b06 & 107 & 0.629 & 4-b14 \\
\hline 8 & 0.117 & 3-b19 & 33 & 0.296 & 4-b15 & 58 & 0.401 & 3-b02 & 83 & 0.540 & $3-c 32$ & 108 & 0.635 & 3-C01 \\
\hline 9 & 0.118 & 2-b19 & 34 & 0.311 & 4-b07 & 59 & 0.411 & 2-b17 & 84 & 0.540 & $2-c 32$ & 109 & 0.639 & 4-b18 \\
\hline 10 & 0.126 & $2-b 20$ & 35 & 0.314 & 3-b17 & 60 & 0.421 & 3-b21 & 85 & 0.540 & 4-b09 & 110 & 0.643 & 2-C01 \\
\hline 11 & 0.126 & 3-b12 & 36 & 0.316 & $1-b 24$ & 61 & 0.421 & 3-b06 & 86 & 0.550 & 4-b02 & 111 & 0.649 & 4-b06 \\
\hline 12 & 0.149 & $3-b 20$ & 37 & 0.329 & $1-b 28$ & 62 & 0.431 & 2-b05 & 87 & 0.551 & $2-c 01$ & 112 & 0.661 & $1-b 22$ \\
\hline 13 & 0.150 & 3-b07 & 38 & 0.332 & 1-b19 & 63 & 0.432 & 3-b25 & 88 & 0.555 & 1-b09 & 113 & 0.683 & 4-c01 \\
\hline 14 & 0.151 & $3-b 23$ & 39 & 0.352 & 2-b09 & 64 & 0.437 & 4-b16 & 89 & 0.556 & 1-C01 & 114 & 0.687 & 4-b17 \\
\hline 15 & 0.151 & 2-b07 & 40 & 0.356 & 2-b13 & 65 & 0.442 & 3-b01 & 90 & 0.556 & $1-c 31$ & 115 & 0.703 & 3-B01 \\
\hline 16 & 0.165 & $2-b 23$ & 41 & 0.358 & 1-b16 & 66 & 0.452 & 2-b02 & 91 & 0.572 & $1-b 21$ & 116 & 0.728 & $4-b 27$ \\
\hline 17 & 0.175 & 3-b08 & 42 & 0.362 & 3-b14 & 67 & 0.473 & 1-b26 & 92 & 0.574 & 3-c01 & 117 & 0.729 & $4-b 21$ \\
\hline 18 & 0.176 & $2-b 08$ & 43 & 0.367 & 1-b23 & 68 & 0.474 & $3-b 26$ & 93 & 0.576 & $4-b 23$ & 118 & 0.743 & 1-b05 \\
\hline 19 & 0.202 & $2-b 24$ & 44 & 0.373 & 3-b10 & 69 & 0.475 & $3-b 22$ & 94 & 0.577 & $1-c 32$ & 119 & 0.756 & 1-b10 \\
\hline 20 & 0.205 & $3-b 24$ & 45 & 0.376 & 2-b10 & 70 & 0.476 & 2-b01 & 95 & 0.582 & 4-b13 & 120 & 0.761 & 4-b22 \\
\hline 21 & 0.230 & 2-b04 & 46 & 0.376 & 1-b27 & 71 & 0.480 & 1-b12 & 96 & 0.584 & 4-b01 & 121 & 0.763 & 1-b08 \\
\hline 22 & 0.256 & 3-b03 & 47 & 0.378 & 1-b15 & 72 & 0.480 & $3-\mathrm{c0} 2$ & 97 & 0.599 & $4-b 24$ & 122 & 0.784 & 2-B01 \\
\hline 23 & 0.257 & 3-b04 & 48 & 0.378 & 4-b03 & 73 & 0.483 & $2-\mathrm{c0} 2$ & 98 & 0.599 & $2-c 31$ & 123 & 0.793 & $3-\mathrm{CO} 2$ \\
\hline 24 & 0.268 & 3-b13 & 49 & 0.383 & 4-b12 & 74 & 0.487 & 4-b20 & 99 & 0.600 & 1-b14 & 124 & 0.815 & $2-\mathrm{CO} 2$ \\
\hline 25 & 0.269 & $3-b 27$ & 50 & 0.384 & 3-b18 & 75 & 0.495 & 1-b11 & 100 & 0.609 & 4-b10 & 125 & 0.944 & 1-B01 \\
\hline
\end{tabular}

Table 4 Failure path for Model II.

\begin{tabular}{|c|c|c|c|c|c|c|c|c|c|c|c|c|c|c|}
\hline $\begin{array}{l}\text { Yield } \\
\text { Order }\end{array}$ & $\zeta_{\text {WRSR }}$ & $\begin{array}{c}\text { Section } \\
\text { Label }\end{array}$ & $\begin{array}{l}\text { Yield } \\
\text { Order }\end{array}$ & $\zeta_{\text {WRSR }}$ & $\begin{array}{c}\text { Section } \\
\text { Label }\end{array}$ & $\begin{array}{l}\text { Yield } \\
\text { Order }\end{array}$ & $\zeta_{W R S R}$ & $\begin{array}{c}\text { Section } \\
\text { Label }\end{array}$ & $\begin{array}{l}\text { Yield } \\
\text { Order }\end{array}$ & $\zeta_{\text {WRSR }}$ & $\begin{array}{c}\text { Section } \\
\text { Label }\end{array}$ & $\begin{array}{l}\text { Yield } \\
\text { Order }\end{array}$ & $\zeta_{\text {WRSR }}$ & $\begin{array}{c}\text { Section } \\
\text { Label }\end{array}$ \\
\hline 1 & 0.147 & 3-b09 & 16 & 0.233 & 2-b05 & 31 & 0.324 & 3-b18 & 46 & 0.477 & 4-b07 & 61 & 0.564 & $3-b 22$ \\
\hline 2 & 0.153 & 2-b09 & 17 & 0.237 & 2-b15 & 32 & 0.342 & 1-b27 & 47 & 0.477 & 4-b05 & 62 & 0.587 & 4-b04 \\
\hline 3 & 0.158 & 2-b10 & 18 & 0.238 & 3-b05 & 33 & 0.345 & 2-b18 & 48 & 0.479 & 4-b09 & 63 & 0.597 & $2-b 28$ \\
\hline 4 & 0.162 & 3-b11 & 19 & 0.243 & 2-b08 & 34 & 0.374 & $3-b 21$ & 49 & 0.510 & 4-b10 & 64 & 0.627 & $4-b 20$ \\
\hline 5 & 0.174 & 3-b12 & 20 & 0.244 & 3-b08 & 35 & 0.416 & $3-b 24$ & 50 & 0.517 & 3-b02 & 65 & 0.630 & $3-b 28$ \\
\hline 6 & 0.187 & 2-b12 & 21 & 0.246 & 2-b06 & 36 & 0.421 & $2-b 04$ & 51 & 0.517 & 1-b19 & 66 & 0.640 & 4-b03 \\
\hline 7 & 0.188 & 2-b14 & 22 & 0.251 & 3-b07 & 37 & 0.433 & $2-b 21$ & 52 & 0.518 & 1-b15 & 67 & 0.660 & $2-b 22$ \\
\hline 8 & 0.188 & 3-b16 & 23 & 0.262 & 3-b17 & 38 & 0.441 & $3-b 23$ & 53 & 0.521 & $1-b 23$ & 68 & 0.678 & 4-b14 \\
\hline 9 & 0.191 & 3-b10 & 24 & 0.262 & 3-b19 & 39 & 0.444 & 4-b12 & 54 & 0.533 & 4-b15 & 69 & 0.683 & $2-b 25$ \\
\hline 10 & 0.195 & 2-b11 & 25 & 0.277 & $2-b 07$ & 40 & 0.444 & $2-b 02$ & 55 & 0.539 & $2-b 23$ & 70 & 0.716 & 4-b02 \\
\hline 11 & 0.196 & 3-b13 & 26 & 0.292 & 2-b17 & 41 & 0.446 & 3-b04 & 56 & 0.544 & 4-b16 & 71 & 0.728 & $3-b 27$ \\
\hline 12 & 0.199 & 2-b16 & 27 & 0.294 & $2-b 20$ & 42 & 0.447 & $2-b 24$ & 57 & 0.546 & 4-b06 & 72 & 0.754 & 4-b19 \\
\hline 13 & 0.208 & 3-b15 & 28 & 0.300 & 3-b06 & 43 & 0.452 & $2-\mathrm{b} 03$ & 58 & 0.547 & 4-b13 & 73 & 0.840 & $3-b 26$ \\
\hline 14 & 0.216 & 3-b14 & 29 & 0.312 & $3-b 20$ & 44 & 0.458 & 4-b08 & 59 & 0.550 & 3-b03 & 74 & 0.840 & $1-b 25$ \\
\hline 15 & 0.218 & 2-b13 & 30 & 0.322 & 2-b19 & 45 & 0.475 & 4-b11 & 60 & 0.559 & $3-b 25$ & 75 & 0.880 & $1-b 11$ \\
\hline
\end{tabular}

Plastic deformations are mainly concentrated on the sub-beams of the second, third, and fourth sub-frames. The histogram in Figure 5 shows the frequency of occurrence of plastic deformation on each investigation section on these sub-beams under the 50 different seismic waves. Most of the sections in Model I are prone to plastic deformation. Some sections yielded in $\mathbf{4 9}$ out of the $\mathbf{5 0}$ waves. The distribution of bars in Model II and III histograms is significantly different from that for Model I. For Model II and III, plastic deformation often occurs in the middle floors of each sub-frame and rarely on the top and bottom floors. Among the three released sub-frames, the third sub-frame suffers the most damage. Model III is the structure with the least number of plastic deformation. 
The weak sections and floors shall be designed with emphasis. The member sizes should be increased. On the other hand, for those sections that have never yielded, their size can be reduced to distribute materials more reasonably and obtain consistent seismic reliability.

Table 5 Yield order and $\zeta_{\text {WRSR }}$ for investigation sections of Model III.

\begin{tabular}{|c|c|c|c|c|c|c|c|c|}
\hline Yield Order & $\zeta_{W R S R}$ & Section Label & Yield Order & $\zeta_{\text {WRSR }}$ & Section Label & Yield Order & $\zeta_{\text {WRSR }}$ & Section Label \\
\hline 1 & 0.083 & 2-b09 & 23 & 0.243 & 2-b16 & 45 & 0.430 & $1-b 25$ \\
\hline 2 & 0.084 & $2-b 07$ & 24 & 0.256 & $2-b 20$ & 46 & 0.475 & 4-b10 \\
\hline 3 & 0.085 & $2-b 11$ & 25 & 0.258 & 2-b06 & 47 & 0.485 & 4-b04 \\
\hline 4 & 0.088 & $2-b 10$ & 26 & 0.286 & 3-b06 & 48 & 0.496 & $3-b 22$ \\
\hline 5 & 0.088 & $2-b 05$ & 27 & 0.291 & 3-b19 & 49 & 0.509 & 4-b15 \\
\hline 6 & 0.111 & $2-b 12$ & 28 & 0.293 & 3-b14 & 50 & 0.511 & 4-b13 \\
\hline 7 & 0.122 & $2-b 13$ & 29 & 0.318 & $2-b 17$ & 51 & 0.522 & $2-b 23$ \\
\hline 8 & 0.123 & $2-b 15$ & 30 & 0.328 & 3-b04 & 52 & 0.524 & 4-b06 \\
\hline 9 & 0.134 & 3-b11 & 31 & 0.340 & 4-b07 & 53 & 0.528 & 4-b03 \\
\hline 10 & 0.151 & 3-b09 & 32 & 0.342 & 4-b05 & 54 & 0.531 & $3-b 24$ \\
\hline 11 & 0.158 & 3-b07 & 33 & 0.347 & $3-b 20$ & 55 & 0.546 & $3-b 23$ \\
\hline 12 & 0.166 & $2-b 14$ & 34 & 0.347 & $1-b 23$ & 56 & 0.554 & 3-b02 \\
\hline 13 & 0.169 & 3-b05 & 35 & 0.349 & 2-b18 & 57 & 0.569 & 4-b16 \\
\hline 14 & 0.172 & $1-b 27$ & 36 & 0.355 & 3-b03 & 58 & 0.648 & $3-b 21$ \\
\hline 15 & 0.187 & 3-b12 & 37 & 0.364 & 3-b17 & 59 & 0.652 & $2-b 21$ \\
\hline 16 & 0.196 & 3-b15 & 38 & 0.376 & 4-b09 & 60 & 0.670 & 4-b14 \\
\hline 17 & 0.213 & 3-b08 & 39 & 0.381 & 1-b15 & 61 & 0.678 & 4-b02 \\
\hline 18 & 0.221 & 3-b13 & 40 & 0.382 & 4-b11 & 62 & 0.728 & 4-b19 \\
\hline 19 & 0.222 & 3-b16 & 41 & 0.401 & 4-b12 & 63 & 0.750 & $3-b 27$ \\
\hline 20 & 0.224 & 2-b08 & 42 & 0.402 & 4-b08 & 64 & 0.841 & 3-B01 \\
\hline 21 & 0.226 & 3-b10 & 43 & 0.412 & 3-b18 & 65 & 0.852 & 4-b17 \\
\hline 22 & 0.240 & 2-b19 & 44 & 0.415 & 1-b19 & 66 & 0.856 & 1-b11 \\
\hline
\end{tabular}

\section{Seismic behavior matrices}

Based on the calculation results of the failure paths in the previous section, further research is conducted on the structural behavior of MSCSS. Because the number of investigation sections for all three models is too large, and the method of constructing behavior matrices is similar, only the results of Model III are shown. Since plastic hinges rarely appear on the mega-frame, this section focuses on the sub-frames in Model III.

Table 6 shows the average maximum SDR of the second, third, and fourth sub-frames under 50 seismic waves. Trends of the values on different floors are illustrated in Figure 6.

Table 6 Average SDRs for upper three sub-frames of Model III.

\begin{tabular}{ccccccccc}
\hline \multirow{2}{*}{ Sub-frame } & \multicolumn{7}{c}{ Sub-story } \\
\cline { 2 - 8 } & $\mathbf{1}$ & $\mathbf{2}$ & $\mathbf{3}$ & $\mathbf{4}$ & $\mathbf{5}$ & $\mathbf{6}$ & $\mathbf{7}$ \\
\hline 2nd & 0.0045 & 0.0091 & 0.0111 & 0.0113 & 0.0105 & 0.0088 & 0.0074 \\
3rd & 0.0054 & 0.0108 & 0.0133 & 0.0135 & 0.0124 & 0.0102 & 0.0076 \\
4th & 0.0058 & 0.0110 & 0.0126 & 0.0117 & 0.0094 & 0.0066 & 0.0041 \\
\hline
\end{tabular}




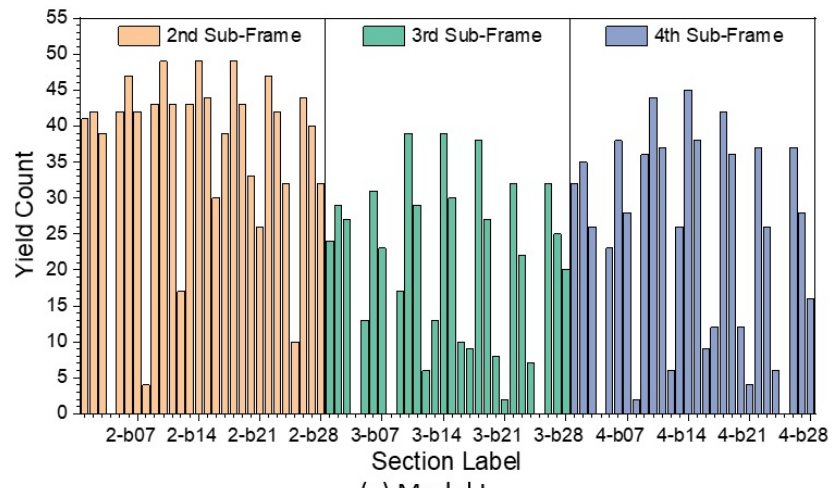

(a) Model I

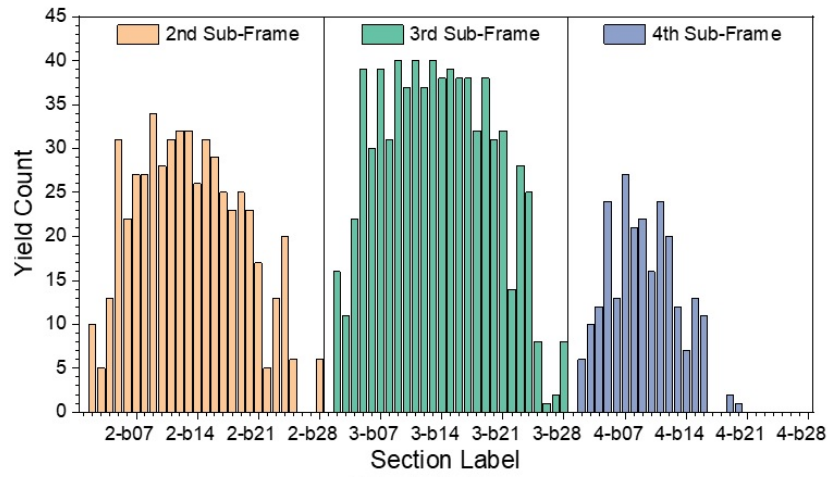

(b) Model II

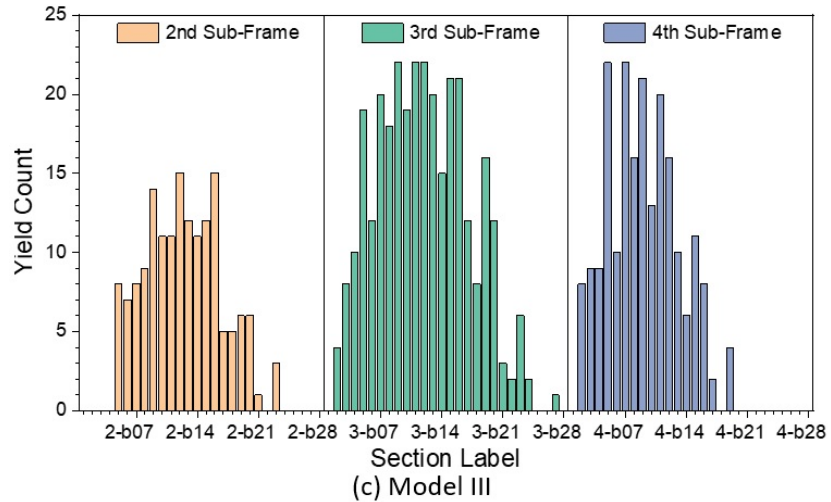

Figure 5 Frequency of occurrence of plastic deformation at each investigation section.

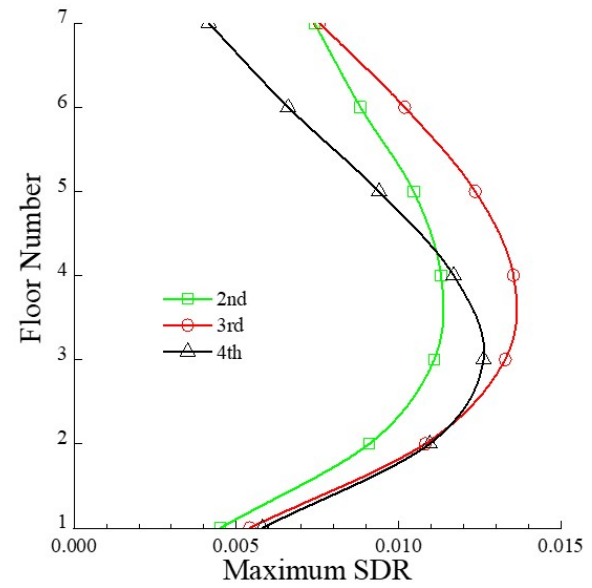

Figure 6 Trends of average maximum SDRs for three sub-frames. 
By combining the yield orders with the SDRs, the structural seismic behavior matrices for the second, third, and fourth sub-frames of Model III are obtained and shown below. They are denoted as $\mathbf{r}_{2}, \mathbf{r}_{3}$, and $\mathbf{r}_{4}$, respectively. The matrices are arranged as follows: the first columns are the SDRs on each floor; the second to the fifth columns are the yield order numbers for sub-beams, and the rest are the yield order numbers for sub-columns. Since investigation sections on sub-columns have never yielded, their corresponding yield order numbers are all zeros in the matrices.

$\mathbf{r}_{2}=\left[\begin{array}{ccccccccccc}0.0045 & 0 & 0 & 0 & 0 & 0 & 0 & 0 & 0 & 0 & 0 \\ 0.0091 & 3 & 15 & 4 & 20 & 0 & 0 & 0 & 0 & 0 & 0 \\ 0.0111 & 1 & 2 & 13 & 12 & 0 & 0 & 0 & 0 & 0 & 0 \\ 0.0113 & 10 & 8 & 17 & 24 & 0 & 0 & 0 & 0 & 0 & 0 \\ 0.0105 & 29 & 35 & 25 & 23 & 0 & 0 & 0 & 0 & 0 & 0 \\ 0.0088 & 54 & 0 & 48 & 0 & 0 & 0 & 0 & 0 & 0 & 0 \\ 0.0074 & 0 & 0 & 0 & 0 & 0 & 0 & 0 & 0 & 0 & 0\end{array}\right]$

$\mathbf{r}_{3}=\left[\begin{array}{ccccccccccc}0.0054 & 0 & 49 & 28 & 33 & 0 & 0 & 0 & 0 & 0 & 0 \\ 0.0108 & 9 & 22 & 7 & 16 & 0 & 0 & 0 & 0 & 0 & 0 \\ 0.0133 & 6 & 19 & 5 & 11 & 0 & 0 & 0 & 0 & 0 & 0 \\ 0.0135 & 18 & 26 & 14 & 21 & 0 & 0 & 0 & 0 & 0 & 0 \\ 0.0124 & 34 & 40 & 27 & 32 & 0 & 0 & 0 & 0 & 0 & 0 \\ 0.0102 & 53 & 50 & 51 & 52 & 0 & 0 & 0 & 0 & 0 & 0 \\ 0.0076 & 0 & 0 & 58 & 0 & 0 & 0 & 0 & 0 & 0 & 0\end{array}\right]$

$\mathbf{r}_{4}=\left[\begin{array}{ccccccccccc}0.0058 & 0 & 55 & 45 & 42 & 0 & 0 & 0 & 0 & 0 & 0 \\ 0.0110 & 30 & 44 & 31 & 39 & 0 & 0 & 0 & 0 & 0 & 0 \\ 0.0126 & 38 & 41 & 37 & 36 & 0 & 0 & 0 & 0 & 0 & 0 \\ 0.0117 & 46 & 56 & 43 & 47 & 0 & 0 & 0 & 0 & 0 & 0 \\ 0.0094 & 59 & 0 & 57 & 0 & 0 & 0 & 0 & 0 & 0 & 0 \\ 0.0066 & 0 & 0 & 0 & 0 & 0 & 0 & 0 & 0 & 0 & 0 \\ 0.0041 & 0 & 0 & 0 & 0 & 0 & 0 & 0 & 0 & 0 & 0\end{array}\right]$

From Figure 6 and the seismic behavior matrices of Model III, it can be seen that, among the three sub-frames, the SDRs of the third sub-frame exceeds that of the other two sub-frames. In each sub-frame, the SDRs of the middle stories exceed those of the top and bottom stories. In most cases, plastic hinges are more likely to occur on floors with large SDRs. However, SDR and the sequence of plastic hinge formation are not always positively related. For example, in the second and third floors of the second sub-frame, the plastic hinges are formed early compared with the other sub-frames, although the SDR is small. The behavior matrix contains detailed information that cannot be deduced from the SDR. The significance of structural behavior in seismic design is that it allows designers to control the SDR for the overall structure and observe the order of failure of each structural member; so that designers can have a more detailed understanding of the failure process of structures under earthquake.

\section{Conclusions}

This paper focuses on the failure process of MSCSS under earthquake action. The weighted rank-sum ratio method is used to calculate the most probable failure path. By combining the failure path and the SDR, the concept of structural seismic behavior is proposed, and it is mathematically described by the seismic behavior matrix.

Through the analysis of the failure path and seismic behavior, the following conclusions can be drawn about the studied models: 
1. The second and third sub-frames located in the middle of the height of MSCSS yield first and suffer the worst damage. The design of these sub-frames shall be emphasized. The uppermost sub-frame yields later and less. The lowermost sub-frame rarely yields in the selected seismic waves. For each released sub-frames, the yielding of members starts from the ends of sub-beams of the second and third sub-stories.

2. Compared with traditional MSS, MSCSS has significantly fewer members yielded under the same seismic waves, and the mega-frame for MSCSS remains intact after the earthquakes. For MCSCC with rubber bearings, the seismic performance is further improved compared to ordinary MCSCC. The MCSCC with rubber bearings has the least number of yielded sections in the three structural forms.

3. The structural seismic behavior matrix contains the failing sequence information of members that cannot be conveyed by the SDR. The behavior matrix shows both the weak floors of the structure and the weak members in each floor. In the future research, the behavior matrix can be imported into a computer program and used as a target for structural member size optimization.

\section{Acknowledgments}

The research is financially supported by the National Natural Science Foundation of China (Grant No. 51878274).

Author's Contribuitions: Conceptualization, Xun'an Zhang; Methodology, Buqiao Fan and Muhammad Moman; Investigation, Buqiao Fan; Writing - original draft, Buqiao Fan; Writing - review \& editing, Mustapha Abdulhadi and Zhihao Wang; Funding acquisition, Zhihao Wang; Resources, Zhihao Wang; Supervision, Xun'an Zhang.

Editor: Marcílio Alves

\section{References}

Abdulhadi, M., Zhang, X., Fan, B., Moman, M., (2020). Design, Optimization and Nonlinear Response Control Analysis of the Mega Sub-Controlled Structural System (MSCSS) Under Earthquake Action. Journal of Earthquake and Tsunami.

Chau, V., Rougier, E., Lei, Z., Knight, E.E., Gao, K., Hunter, A., Srinivasan, G., Viswanathan, H., (2020). Numerical analysis of flyer plate experiments in granite via the combined finite-discrete element method. Computational Particle Mechanics 7, 10051016.

Chen, X., Li, A., Zhang, Z., Hu, L., Sun, P., Fan, Z., Liu, X., (2019). Improving the wind-induced human comfort of the Beijing Olympic Tower by a double-stage pendulum tuned mass damper. Structural Design of Tall and Special Buildings e1704.

Deringol, A.H., Bilgin, H., (2018). Effects of the isolation parameters on the seismic response of steel frames. Earthquakes and Structures 15, 319-334.

Dona, M., Bernardi, E., Zonta, A., Tan, P., Zhou, F., (2021). Evaluation of optimal FVDs for inter-storey isolation systems based on surrogate performance models. Bulletin of Earthquake Engineering 19, 4587-4621.

Elias, S., Matsagar, V., (2017). Effectiveness of Tuned Mass Dampers in Seismic Response Control of Isolated Bridges Including Soil-Structure Interaction. Latin American Journal of Solids and Structures 14, 2324-2341.

Espinoza, G., Benedetti, F., Alvarez-Mendoza, P., Bonilla, E., (2018a). Influence of the Seismic Excitation Frequencies Content on the Behavior of a Tuned Mass Damper in Low-Rise Building Considering Soil-Structure Interaction. Latin American Journal of Solids and Structures 15, e75.

Espinoza, G., Carrillo, C., Suazo, A., (2018b). Analysis of a tuned liquid column damper in non-linear structures subjected to seismic excitations. Latin American Journal of Solids and Structures 15, e91.

Fan, B., Zhang, X., Abdulhadi, M., Wang, Z., (2020). Generic optimization, energy analysis, and seismic response study for MSCSS with rubber bearings. Earthquakes and Structures 19, 347-359.

Fan, G., Zhang, L.M., Zhang, J.-J., Ouyang, F., (2017). Energy-Based Analysis of Mechanisms of Earthquake-Induced Landslide Using Hilbert-Huang Transform and Marginal Spectrum. Rock Mechanics and Rock Engineering 50, 2425-2441. 
Feng, M.Q., Chai, W., (1997). Design of a mega-sub-controlled building system under stochastic wind loads. Probabilistic Engineering Mechanics 12, 149-162.

Feng, M.Q., Mita, A., (1995). Vibration Control of Tall Buildings Using Mega Subconfiguration. Journal of Engineering Mechanics-Asce 121, 1082-1088.

Fu, X., Chen, H., Cai, R., Yang, P., (2015). Optimal allocation and adaptive VAR control of PV-DG in distribution networks. Applied Energy 137, 173-182.

Fu, X., Du, W.L., Li, H.N., Li, G., Dong, Z.Q., Yang, L.D., (2020). Stress state and failure path of a tension tower in a transmission line under multiple loading conditions. Thin-Walled Structures 157, 107012.

Fu, X., Li, H.N., (2018). Uncertainty analysis of the strength capacity and failure path for a transmission tower under a wind load. Journal of Wind Engineering and Industrial Aerodynamics 173, 147-155.

Garcia, S.R., Romo, M.P., Alcantara, L., (2019). Analysis of non-linear and non-stationary seismic recordings of Mexico city. Soil Dynamics and Earthquake Engineering 127, 105859.

GB50011, (2010). Code for Seismic Design of Buildings. Ministry of Housing and Urban-Rural Development of the People's Republic of China, Beijing, China.

Gu, W., Zhao, Y., Li, Q., Li, Y., (2020). Plant-microorganism combined remediation of polychlorinated naphthalenes contaminated soils based on molecular directed transformation and Taguchi experimental design-assisted dynamics simulation. Journal of Hazardous Materials 396, 122753.

Hessabi, R.M., Mercan, O., Ozturk, B., (2017). Exploring the effects of tuned mass dampers on the seismic performance of structures with nonlinear base isolation systems. Earthquakes and Structures 12, 285-296.

Hwang, J.S., Chiou, J.M., (1996). An equivalent linear model of lead-rubber seismic isolation bearings. Engineering Structures $18,528-536$.

Jangid, R., Datta, T., (1995). Performance of Base-Isolation Systems for Asymmetric Building Subject to Random-Excitation. Engineering Structures 17, 443-454.

Jangid, R.S., (2007). Optimum lead-rubber isolation bearings for near-fault motions. Engineering Structures 29, $2503-2513$.

Kilar, V., Koren, D., (2009). Seismic behaviour of asymmetric base isolated structures with various distributions of isolators. Engineering Structures 31, 910-921.

Kim, H.S., Kang, J.W., (2019). Optimal design of smart mid-story isolated control system for a high-rise building. International Journal of Steel Structures 19, 1988-1995.

Kontoni, D.P.N., Farghaly, A.A., (2019). The effect of base isolation and tuned mass dampers on the seismic response of RC high-rise buildings considering soil-structure interaction. Earthquakes and Structures 17, 425-434.

Li, Q.S., Zhi, L.H., Tuan, A.Y., Kao, C.S., Su, S.C., Wu, C.F., (2011). Dynamic behavior of Taipei 101 Tower: field measurement and numerical analysis. Journal of Structural Engineering-Asce 137, 143-155.

Limazie, T., Zhang, X.A., Wang, X.J., (2013). Vibration control parameters investigation of the Mega-Sub Controlled Structure System (MSCSS). Earthquakes and Structures 5, 225-237.

Liu, Y., Wu, J., Dona, M., (2018). Effectiveness of fluid-viscous dampers for improved seismic performance of inter-storey isolated buildings. Engineering Structures 169, 276-292.

Mishra, S.K., Roy, B.K., Chakraborty, S., (2013). Reliability-based-design-optimization of base isolated buildings considering stochastic system parameters subjected to random earthquakes. International Journal of Mechanical Sciences 75, 123-133.

Providakis, C.P., (2008). Effect of LRB isolators and supplemental viscous dampers on seismic isolated buildings under nearfault excitations. Engineering Structures 30, 1187-1198.

Reggio, A., De Angelis, M., (2015). Optimal energy-based seismic design of non-conventional Tuned Mass Damper (TMD) implemented via inter-story isolation. Earthquake Engineering \& Structural Dynamics 44, 1623-1642.

Ryan, K.L., Earl, C.L., (2010). Analysis and Design of Inter-Story Isolation Systems with Nonlinear Devices. Journal of Earthquake Engineering 14, 1044-1062. 
Sadek, F., Mohraz, B., Taylor, A.W., Chung, R.M., (1997). A method of estimating the parameters of tuned mass dampers for seismic applications. Earthquake Engineering \& Structural Dynamics 26, 617-635.

Sang, S., Wang, Z., Yu, C., (2014). Evaluation of Health Care System Reform in Hubei Province, China. International Journal of Environmental Research and Public Health 11, 2262-2277.

Shao, Y., Billington, S.L., (2020). Flexural performance of steel-reinforced engineered cementitious composites with different reinforcing ratios and steel types. Construction and Building Materials 231, 117159.

Snamina, J., Orkisz, P., (2021). Active vibration reduction system with mass damper tuned using the sliding mode control algorithm. Journal of Low Frequency Noise Vibration and Active Control 40, 540-554.

Soto, M.G., Adeli, H., (2013). Tuned Mass Dampers. Archives of Computational Methods in Engineering 20, $419-431$.

Tan, P., Huang, J., Chang, C.-M., Zhang, Y., (2017). Failure modes of a seismically isolated continuous girder bridge. Engineering Failure Analysis 80, 57-78.

Tian, F., (1993). Application of Rank Sum Ratio Method in the Prediction of Disease Epidemic. Chinese Public Health 47-40. (In Chinese)

Tian, X., Zhang, S., Awbi, H.B., Liao, C., Cheng, Y., Lin, Z., (2020). Multi-indicator evaluation on ventilation effectiveness of three ventilation methods: An experimental study. Building and Environment 180, 107015.

Warn, G.P., Ryan, K.L., (2012). A Review of Seismic Isolation for Buildings: Historical Development and Research Needs. Buildings 2, 300-325.

Zhang, J., (2019). Locally exact discretization method for nonlinear oscillation systems. Journal of Low Frequency Noise Vibration and Active Control 38, 1567-1575.

Zhang, X.A., Qin, X.J., Cherry, S., Lian, Y.D., Zhang, J.L., Jiang, J.S., (2009). A New Proposed Passive Mega-Sub Controlled Structure and Response Control. Journal of Earthquake Engineering 13, 252-274.

Zhang, X.A., Wang, D., Jiang, J.S., (2005). The controlling mechanism and the controlling effectiveness of passive mega-subcontrolled frame subjected to random wind loads. Journal of Sound and Vibration 283, 543-560.

Zhou, Z., Wei, X., Lu, Z., Jeremic, B., (2018). Influence of soil-structure interaction on performance of a super tall building using a new eddy-current tuned mass damper. The Structural Design of Tall and Special Buildings 27, e1501.

Zhu, X., Xu, Q., Liu, H.X., (2017). Using Hilbert-Huang Transform (HHT) to Extract Infrasound Generated by the 2013 Lushan Earthquake in China. Pure and Applied Geophysics 174, 865-874. 